Article

\title{
Wolbachia Affects Reproduction and Population Dynamics of the Coffee Berry Borer (Hypothenemus hampei): Implications for Biological Control
}

\author{
Yobana A. Mariño ${ }^{1, *}$, José C. Verle Rodrigues ${ }^{2}$ and Paul Bayman ${ }^{1}$ \\ 1 Department of Biology, University of Puerto Rico-Río Piedras, San Juan, PR 00931, USA; \\ bayman.upr@gmail.com \\ 2 Center for Excellence in Quarantine and Invasive Species, Agricultural Experimental Station—Río Piedras, \\ Department of Agroenvironmental Sciences, University of Puerto Rico-Mayagüez, 1193 Calle Guayacán, \\ San Juan, PR 00926, USA; jose_carlos@mac.com \\ * Correspondence: yandreamarinoc@gmail.com or yobana.marino@upr.edu; Tel.: +1-787-466-1941
}

Academic Editors: Eric W. Riddick and Andrew G. S. Cuthbertson

Received: 2 September 2016; Accepted: 5 January 2017; Published: 11 January 2017

\begin{abstract}
Wolbachia are widely distributed endosymbiotic bacteria that influence the reproduction and fitness of their hosts. In recent years the manipulation of Wolbachia infection has been considered as a potential tool for biological control. The coffee berry borer (CBB), Hypothenemus hampei, is the most devastating coffee pest worldwide. Wolbachia infection in the CBB has been reported, but until now the role of Wolbachia in CBB reproduction and fitness has not been tested. To address this issue we reared the CBB in artificial diets with and without tetracycline $(0.1 \% \mathrm{w} / \mathrm{v})$ for ten generations. Tetracycline reduced significantly the relative proportion of Wolbachia in the CBB microbiota from $0.49 \%$ to $0.04 \%$. This reduction affected $\mathrm{CBB}$ reproduction: females fed with tetracycline had significantly fewer progeny, lower fecundity, and fewer eggs per female. Tetracycline also reduced the population growth rate $(\lambda)$, net reproductive rate $\left(R_{0}\right)$, and mean generation time $(\mathrm{T})$ in CBB; the reduction in population growth was mostly due to variation in fertility, according to life time response experiments (LTREs) analysis. Our results suggest that Wolbachia contribute to the reproductive success of the $\mathrm{CBB}$ and their manipulation represents a possible approach to $\mathrm{CBB}$ biocontrol mediated by microbiome management.
\end{abstract}

Keywords: biological control; coffee; coffee berry borer; Hypothenemus hampei; population dynamics; sex ratio; Wolbachia

\section{Introduction}

Wolbachia is the most-widely studied genus of endosymbiotic bacteria that infect insects. Wolbachia species are cytoplasmically inherited. They are known as reproductive parasites; since they manipulate the reproduction of their hosts in order to enhance their own transmission [1-3]. Reproductive manipulations include four mechanisms; cytoplasmic incompatibility, parthenogenesis, feminization, and male killing [4-7]. However, the relation of Wolbachia and their insect hosts also can be mutualistic; several studies have shown that infection with Wolbachia may be necessary for the normal reproduction of their hosts [8-14]. For example, in some species of beetles (Family Curculionidae) the elimination of Wolbachia with antibiotics significantly reduced fecundity, and in some cases eggs laid by cured females were not viable [11,13]. 
The potential role of Wolbachia in biological control has received attention in recent years. Infection with Wolbachia can be manipulated to increase populations of beneficial insects such as parasitoids or to reduce populations of pests $[2,15]$.

The coffee berry borer (CBB) Hypothenemus hampei (Ferrari), (Coleoptera: Curculionidae) is the most devastating pest of coffee worldwide [16-19]. CBB females tunnel through the fruit until they reach the endosperm, where they oviposit [16,19]. The entire life cycle occurs inside the fruit and the only stage susceptible to CBB management is when the fertilized females leave the fruit to search for another fruit to colonize. This cryptic life cycle and resistance to insecticides such as endosulfan make CBB control extremely difficult and expensive.

Infection of CBB with Wolbachia has been reported in adult females from several countries [20]. It is thought to induce cytoplasmic incompatibility and to distort the CBB's sex ratio towards females [20]. However, the effect of elimination of Wolbachia on sex ratio and other reproductive traits has not been tested in CBB. The objectives of this study were to determine the infection status of Wolbachia in females from Puerto Rico, and test (by treatment with antibiotics) the effect of removal of Wolbachia on CBB reproduction, sex ratio, and population dynamics.

\section{Materials and Methods}

\subsection{Insect Rearing}

Coffee berry borers were reared for ten consecutive generations on the Cenibroca artificial diet [21]. Approximately $10 \mathrm{~mL}$ of diet was placed in sterile, clear plastic vials $(23 \mathrm{~mm} \times 92 \mathrm{~mm}$, with a plug of bonded dense-weave cellulose acetate, Genessee Scientific, San Diego, CA, USA). Insects were reared in the dark in a growth chamber (Model 818, Thermo Scientific, Dubuque, IA, USA) at $25{ }^{\circ} \mathrm{C}\left( \pm 1{ }^{\circ} \mathrm{C}\right)$ and $80 \%-96 \%$ relative humidity. Colonies were maintained in the Center for Excellence in Quarantine and Invasive Species at University of Puerto Rico Agricultural Experimental Station in Río Piedras, PR, USA.

Adult CBB females were collected from infested fruits from arabica coffee in Adjuntas, Puerto Rico $\left(18^{\circ} 10^{\prime} 42.4^{\prime \prime} \mathrm{N}, 66^{\circ} 44^{\prime} 36^{\prime \prime} \mathrm{W}, 527 \mathrm{~m}\right.$ above sea level (masl)). Fruits were carefully dissected with aid of a stereoscope, and females were removed and surface-disinfected by submersion in $1 \%$ sodium hypochlorite for $1 \mathrm{~min}$, followed by two rinses with sterile distilled water. For all generations three females were placed in each vial. After each generation adult females were removed from the diet and mixed (randomized) before disinfection and transferal to fresh diet to begin the next generation.

\subsection{Antibiotics Treatment}

For direct and continuous feeding of larvae and adults, tetracycline hydrochloride and penicillin G (Fisher Bioreagents, Pittsburgh, PA, USA) 0.1\% (w/v) were added to the Cenibroca diet. Tetracycline is efficient at removing Wolbachia [14,22,23]; penicillin is not active against Wolbachia [3,24,25] but sometimes is used to control bacterial growth in insect diets; it was used as a parallel control. An additional control group received no antibiotics.

\subsection{Detection of Wolbachia}

DNA was extracted from the entire bodies of adult females obtained from infested fruits in Adjuntas, Puerto Rico, and from laboratory colonies reared on Cenibroca diet with and without antibiotics. Insects were conserved dry and stored in the freezer at $-20{ }^{\circ} \mathrm{C}$; total DNA was extracted using the DNeasy Plant Mini Kit (Qiagen Sciences, Hilden, Germany).

The presence of Wolbachia in the CBB females was determined by amplification of part of the $w s p$ gene (primers wsp-F: 5' GGGTCCAATAAGTGATGAAGAAAC $3^{\prime}$ and wsp-R: 5' TTAAAA CGCTACTCCAGCTTCTGC $3^{\prime}$ [26] with annealing at $58^{\circ} \mathrm{C}$. Positive controls for PCRs were total DNA of wild Drosophila melanogaster (Meigen) (known to carry Wolbachia) and negative controls were $\mathrm{dH}_{2} \mathrm{O}$. 
PCR products were cleaned on QIAquick columns (Qiagen, Inc., Hilden, Germany) and sequenced in both directions in the University of Puerto Rico Sequencing and Genotyping Facility (UPR-SGF). The resulting sequences were assembled, manually examined for errors using CodonCode Aligner (version 5.1.5; CodonCode Crop., Centerville, SD, USA), and BLASTed in GenBank to compare the CBB sequences with other Wolbachia sequences.

\subsubsection{Phylogenetic Classification in Wolbachia Supergroups}

Phylogenetic analysis was used to assign sequences to Wolbachia supergroups. Three Wolbachia wsp sequences from this study were compared to GenBank reference sequences from 41 species of insects, including CBB [20]. These 41 sequences were selected from Wolbachia supergroups A and B (Table A1) and the sequences from this study were deposited in GenBank (KX436087, KX436088, and KX436089). Sequences were manually aligned with ClustalW in Mesquite [27]. A phylogenetic tree was constructed with Mega 6.0 [28] using neighbor joining, a maximum composite likelihood model, and bootstrap analysis with 1000 replications.

\subsubsection{Relative Proportion of Wolbachia in the CBB Microbiota}

Relative proportions of Wolbachia in the microbiota of adult females from control and tetracycline diets (after eleven generations) were determined using Illumina-based 16S typing. Briefly, pooled DNA from five females, with four replicates per treatment, was extracted using DNeasy Plant Mini Kit (Qiagen Sciences). Bacterial 16S rRNA gene was amplified using the hypervariable region V4 with primers 515-F and 806-R [29] with the addition of barcoding sequences and Illumina (Illumina Inc., San Diego, CA, USA) adapters. Sequencing was done on the Illumina MiSeq platform at UPR-SGF. Sequences were assigned to Wolbachia using OTU (Operational Taxonomic Units) tables generated with QIIME (Quantitative Insights Into Microbial Ecology) [30]. This experiment is described in detail by Mariño [31].

\subsection{Effect of Antibiotic Treatments on CBB Reproduction and Sex Ratio}

For each generation eggs, larvae, pupae, juveniles, and adults in 20 vials per treatment were counted by carefully dissecting the diet from each tube. The sex ratio was calculated as the number of CBB females divided by the number of males. Sex was determined for adult and juveniles by visual inspection of the body and wing shape and size; males are smaller than females and have reduced degenerative wings [16].

To determine the effect of the elimination or reduction of Wolbachia on CBB fecundity, females from the fifth generation of the three treatments were transferred individually to vials with artificial diet ( $n=50$ per treatment); oviposition and number of eggs per female were registered daily for two months.

\subsection{Effect of Antibiotic Treatment on Life Table Parameters of the CBB}

Five cohorts of 20 eggs each were established for each type of diet. Eggs were maintained in the dark at $25^{\circ} \mathrm{C}\left( \pm 1^{\circ} \mathrm{C}\right)$ and a relative humidity of $80 \%-96 \%$. Each cohort was evaluated daily for 50 days at 24-h intervals to determine CBB survival and the transitions to the next stages of development. Also, the development time from egg to adult was determined.

For population dynamics analysis, the basic life cycle for the CBB was defined as egg, larva, pre-pupa, pupa, juvenile, and adult. The probabilities of the projection matrix were calculated at intervals of six days: (Gi) probability of growth or molt between stages, $(P i)$ probability of surviving and remaining in the same stage, and ( $F$ i) fertility of adult females; these values were based on the data obtained in this study for oviposition of fifty females. The probability of adult survival was estimated as 0.99 , because observed mortality of adults was very rare once they emerged; several studies also reported low natural mortality rates in field and laboratory experiments [32-34].

Based on the projection matrix (Equation (1)) for each cohort in the three types of diet, we calculated: the population growth rate $(\lambda)$, the net reproductive value $\left(R_{0}\right)$, and mean generation time (T) [35]. 
A life table response experiment (LTRE) analysis was done to determine the contribution of each life cycle transition in the observed reduction of the population growth rate $(\lambda)$ in CBB populations treated with tetracycline $(0.1 \% \mathrm{w} / \mathrm{v})$ compared with the other two diets (control and penicillin).

\subsection{Data Analysis}

The abundance of individuals in various stages of development of the coffee berry borer and the number of eggs laid per female were estimated using a log-linear model (GLM) with a Poisson distribution; type of diet was defined as an independent variable. Chi-square analysis was used to compare differences in the numbers of females that oviposited among types of diet and to determine differences in the number of reads of Wolbachia found in adult females between tetracycline vs. control diets. One way ANOVAs followed by post-hoc Tukey tests (significance level $p=0.05$ ) were used to test differences among types of diet on sex ratio, life table population parameters, developmental time from egg to adult, and the duration of each stage of development. The package popbio (version 2.4.3) was used to calculate all life table parameters and perform the LTRE analysis [36]. All analyses were performed in $\mathrm{R}$ [37].

\section{Results}

\subsection{Detection of Wolbachia}

$\mathrm{A} \approx 750$-bp fragment was amplified and sequenced from the Wolbachia wsp gene from CBB field-collected and females reared in the laboratory on the Cenibroca diet. The positive control (Drosophila) amplified a band of similar size; no product was amplified in any of the negative controls. Sequences of seven wsp fragments exhibited $100 \%$ sequence similarity to Wolbachia from Drosophila melanogaster (FJ403332).

The wsp sequences from $H$. hampei from Puerto Rico grouped with those of Wolbachia supergroup A. The sequences from CBB formed a separate subclade within supergroup A, closely related to one from a symbiont of the parasitoid Tachinaephagus zealandicus (Ashmead) (DQ380884) [38] (Figure 1). In contrast, a wsp consensus sequence from H. hampei from India and Brazil (AF389084) grouped with supergroup B [20], and with others from the adzuki bean beetle Callasobruchus chinensis (Linnaeus) (AB038339) [26].

\subsection{Effect of Antibiotic Treatment on Wolbachia Infection and CBB Reproduction}

After eleven generations on diet with tetracycline Wolbachia was still detected in CBB. However, the relative proportion of Wolbachia in the CBB microbiota was significantly lower in females from the diet with tetracycline than from the control diet $\left(0.04 \%\right.$ vs. $\left.0.49 \%, \chi^{2}=6265.9, \mathrm{df}=1, p<0.001\right)$.

The log-linear model gave a good fit for the effects of diet on CBB total population $\left(\chi_{7}{ }^{2}=225\right.$, $p<0.0001)$. In general, the estimated population was significantly higher in control and penicillin diets than in tetracycline (Table A2). The estimated population per generation increased independently of type of diet (Table A2). After the $\mathrm{F}_{3}$ generation females reared with tetracycline produced significantly fewer progeny, and in the $\mathrm{F}_{10}$ generation less than half as many individuals were produced compared with control and penicillin diets (Figure 2A). The estimated abundance of individuals at all stages of development varied significantly among diets (GLM, Poisson errors, eggs $Z=232.2, p<0.0001$; larvae $Z=194.7, p<0.0001$, pupae $Z=107.9$, juveniles $Z=52.20, p<0.0001$, and adults $Z=295.4, p<0.0001$ ). In general, the number of individuals in all stages of development was significantly lower in diets with tetracycline than in controls.

The proportion of females that oviposited was significantly lower in diet with tetracycline (38\% in tetracycline, $68 \%$ in control, and $66 \%$ in penicillin, $\chi^{2}=11.50, \mathrm{df}=2, p=0.003$ ). Also, the number of eggs per female was significantly lower in diets with tetracycline: on average, each female laid 3.45 eggs compared with 18.83 in control and 19.58 in penicillin (GLM, Poisson errors, eggs $Z=86.79$, $p<0.0001$ ) (Figure 2B). 
Significant differences were found in sex ratio between diets $(F=6.48, \mathrm{df}=2, p=0.002)$. The sex ratio was less skewed towards females in tetracycline diet than in control and penicillin diets (19.4:1 for tetracycline, 24.1:1 for control, and 26.5:1 for penicillin). These differences in sex ratio were significant from the F3 generation and all subsequent generations; no differences were observed in F1 and F2 (Table 1). However, no differences were observed in the number of males among diets (control vs. penicillin: $Z=1.32, p=0.25$; control vs. tetracycline: $Z=-0.52, p=0.59$ ).

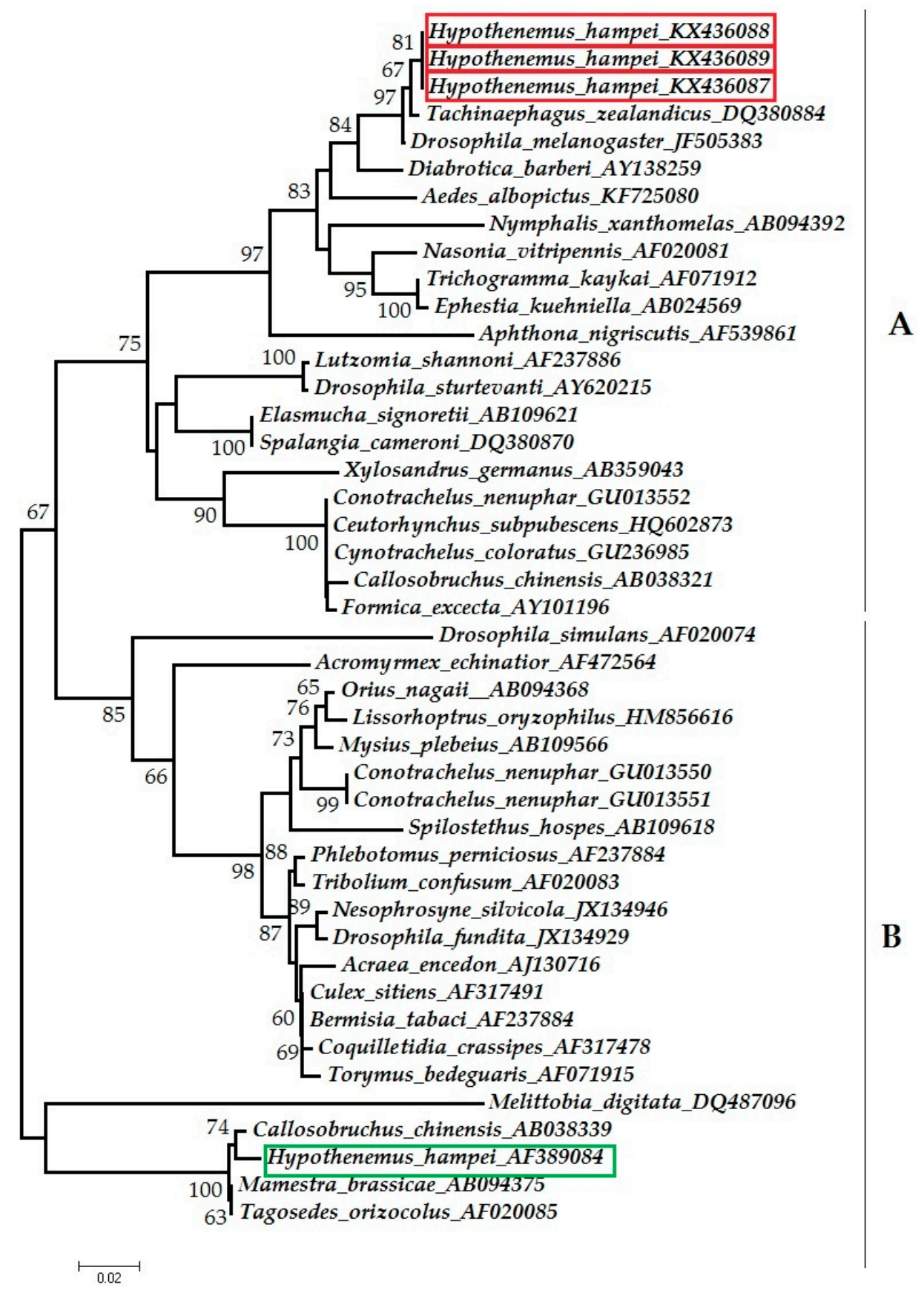

Figure 1. Neighbor-joining tree showing placement of wsp sequences of Wolbachia from Hypothenemus hampei in Wolbachia supergroups A and B. Sequences from this study are shown in red boxes; the sequence from $H$. hampei from Vega et al. [20] is shown in a green box. Reference sequences from endosymbionts of 41 species of insects are included. The tree was constructed using the Maximum Composite Likelihood model and midpoint rooted. Bootstrap probabilities $>50 \%$ are shown at the nodes. GenBank accession numbers are shown. 


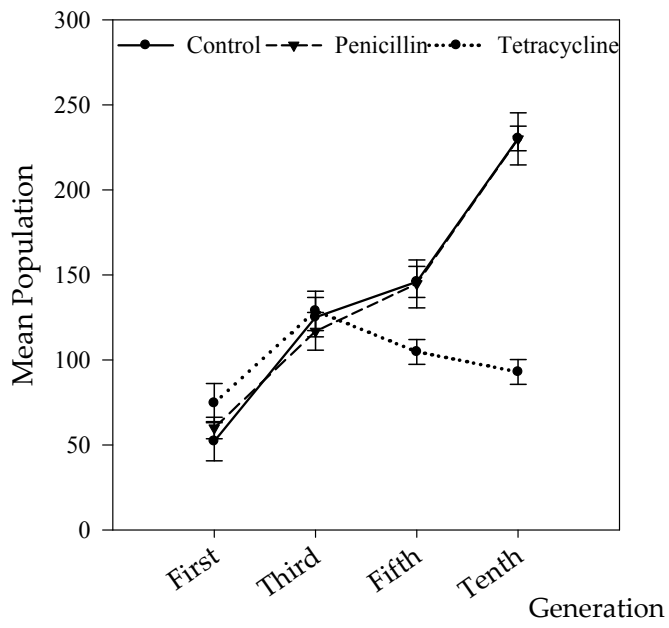

(a)

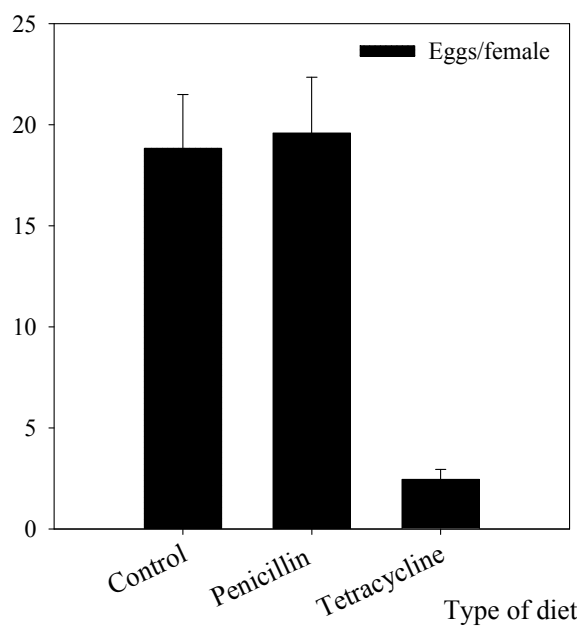

(b)

Figure 2. Effects of antibiotics on Hypothenemus hampei population growth and fecundity. (a) Total number of individuals (including eggs, larvae, pupae, juveniles, and adults) for $F_{1}, F_{3}, F_{5}$, and $F_{10}$ generations (b) Fecundity (number of eggs per female). Means $\pm \mathrm{SE}$ are shown.

Table 1. Number of females, males, and sex ratio of Hypothenemus hampei reared in artificial diets with and without antibiotics; Means $\pm S E$ and $F$ : $M$ ratio per vial for $F_{1}, F_{5}$, and $F_{10}$ generations.

\begin{tabular}{|c|c|c|c|}
\hline \multirow[t]{2}{*}{ Diet } & \multicolumn{3}{|c|}{ Generation $\left(F_{1}\right)$} \\
\hline & Females & Males & Sex Ratio \\
\hline control & $20.8 \pm 1.8$ & $2.4 \pm 0.3$ & $10.2 \pm 0.8 \mathrm{a}$ \\
\hline penicillin & $20.6 \pm 3.4$ & $2.8 \pm 0.4$ & $8.80 \pm 1.2 \mathrm{a}$ \\
\hline tetracycline & $17.5 \pm 2.5$ & $3.5 \pm 0.4$ & $10.3 \pm 1.7 \mathrm{a}$ \\
\hline \multirow[t]{3}{*}{ Statistics } & $Z=61.0 / p=0.04^{a *}$ & $Z=7.29 / p<0.77^{a}$ & $F=0.4 / p=0.66^{b}$ \\
\hline & \multicolumn{3}{|c|}{ Generation $\left(F_{5}\right)$} \\
\hline & Females & Males & Sex Ratio \\
\hline control & $62.0 \pm 4.9$ & $9.4 \pm 0.6$ & $31.0 \pm 2.4 \mathrm{~b}$ \\
\hline penicillin & $39.1 \pm 4.8$ & $5.5 \pm 0.7$ & $19.5 \pm 2.4 \mathrm{a}$ \\
\hline tetracycline & $27.1 \pm 3.5$ & $6.2 \pm 0.7$ & $13.5 \pm 1.7 \mathrm{a}$ \\
\hline \multirow[t]{3}{*}{ Statistics } & $Z=1.05 / p<0.001^{a * * *}$ & $Z=30.5 / p<0.001^{a * * *}$ & $F=16.13 / p<0.001^{\mathrm{b} * * *}$ \\
\hline & \multicolumn{3}{|c|}{ Generation $\left(F_{10}\right)$} \\
\hline & Females & Males & Sex Ratio \\
\hline control & $84.2 \pm 5.1$ & $11.3 \pm 0.8$ & $42.1 \pm 2.5 b$ \\
\hline penicillin & $98.3 \pm 8.6$ & $10.9 \pm 0.8$ & $49.2 \pm 4.3 \mathrm{~b}$ \\
\hline tetracycline & $52.5 \pm 7.2$ & $9.1 \pm 1.1$ & $26.5 \pm 3.6 \mathrm{a}$ \\
\hline Statistics & $Z=182.0 / p<0.001^{a * * *}$ & $Z=36.45 / p=0.74^{\mathrm{a}}$ & $F=10.81 / p=0.0001^{b * * *}$ \\
\hline
\end{tabular}

\subsection{Effect of Antibiotic Treatment on Life Table Parameters of the CBB}

The duration of the juvenile stage was significantly longer in tetracycline than in control and penicillin. However, the duration of the remaining stages did not differ between diets; also, the egg-to-adult developmental time did not differ significantly between diets, but was slightly higher for individuals reared with tetracycline (Table 2). 
Table 2. Developmental time in days (Mean \pm SE) for life stages of the coffee berry borer Hypothenemus hampei reared in artificial diet with and without antibiotics.

\begin{tabular}{ccccccc}
\hline \multirow{2}{*}{ Diet } & \multicolumn{5}{c}{ Development Time (Days) } \\
\cline { 2 - 7 } & Egg & Larva & Pre-Pupa & Pupa & Juvenile & Egg to Adult \\
\hline control & $6.08 \pm 0.22 \mathbf{a}$ & $15.22 \pm 0.75 \mathbf{a}$ & $1.94 \pm 0.11 \mathbf{a}$ & $6.37 \pm 0.15 \mathbf{a}$ & $4.05 \pm 0.12 \mathbf{a}$ & $34.41 \pm 0.75 \mathbf{a}$ \\
penicillin & $6.07 \pm 0.31 \mathbf{a}$ & $15.45 \pm 0.59 \mathbf{a}$ & $1.87 \pm 0.07 \mathbf{a}$ & $6.78 \pm 0.18 \mathbf{a}$ & $4.09 \pm 0.19 \mathbf{a}$ & $34.26 \pm 0.61 \mathbf{a}$ \\
tetracycline & $6.10 \pm 0.21 \mathbf{a}$ & $15.52 \pm 0.74 \mathbf{a}$ & $2.03 \pm 0.09 \mathbf{a}$ & $6.82 \pm 0.26 \mathbf{a}$ & $4.67 \pm 0.24 \mathbf{b}$ & $35.13 \pm 0.94 \mathbf{a}$ \\
Statistics & $F=1.91 / p=0.15$ & $F=0.89 / p=0.41$ & $F=0.86 / p=0.42$ & $F=1.59 / p=0.20$ & $F=3.34 / p=0.01 *$ & $F=0.95 / p=0.38$ \\
\hline
\end{tabular}

Means followed by the same letter within a column are not significantly different ( $p=0.05$, Post-hoc Tukey's test). ${ }^{* * *} p<0.001 ;{ }^{* *} p<0.01 ; * p<0.05 ; p<0.1$.

Life table parameters for the three diets are presented in Table 3. Net reproductive value $R_{0}$ differed significantly among diets (Table 3$)$. The net reproductive value $\left(R_{0}\right)$ was 23 females $/$ female for tetracycline, 51 for control, and 45 for penicillin. In other words, a female on these diets produced on average 23,51 , and 45 new females respectively in each generation.

Table 3. Life table parameters of the coffee berry borer Hypothenemus hampei reared in artificial diet with and without antibiotics.

\begin{tabular}{cccc}
\hline \multirow{2}{*}{ Diet } & \multicolumn{3}{c}{ Life Table Parameters } \\
\cline { 2 - 4 } & $\boldsymbol{\lambda}$ & $\boldsymbol{R}_{\mathbf{0}}$ & $\mathbf{T}$ \\
\hline control & $1.11 \pm 0.01 \mathbf{a}$ & $51.51 \pm 5.72 \mathbf{b}$ & $39.01 \pm 3.13 \mathbf{a}$ \\
penicillin & $1.10 \pm 0.01 \mathbf{a}$ & $45.20 \pm 8.88 \mathbf{a b}$ & $39.19 \pm 5.39 \mathbf{a}$ \\
tetracycline & $1.07 \pm 0.01 \mathbf{a}$ & $23.40 \pm 3.43 \mathbf{a}$ & $45.19 \pm 3.05 \mathbf{a}$ \\
Statistics & $F=3.13 / p=0.08$ & $F=5.29 / p=0.02 *$ & $F=0.77 / p=0.48$ \\
\hline
\end{tabular}

$\lambda=$ population growth rate; $R_{0}=$ net reproductive value; $\mathrm{T}=$ mean generation time. Statistical significance based on ANOVA tests. Means followed by the same letter within a column are not significantly different. $\left(p=0.05\right.$, Post-hoc Tukey's test). ${ }^{* * *} p<0.001 ;{ }^{* *} p<0.01 ;{ }^{*} p<0.05 ; p<0.1$.

For all diets the population growth rate was $>1$, but populations treated with tetracycline had a slightly lower $\lambda$; the LTRE showed that reduction in fecundity of adult females feeding with tetracycline made the largest contribution to the reduction in $\lambda$ (Figure 3). Although differences in the mean generation time $(\mathrm{T})$ were not significant, tetracycline treatment increased the time by 6.2 days, which means that females reared with tetracycline will produce fewer generations per year (Table 3 ).

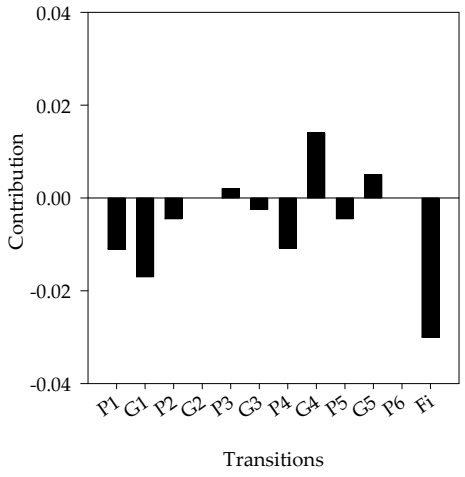

(a)

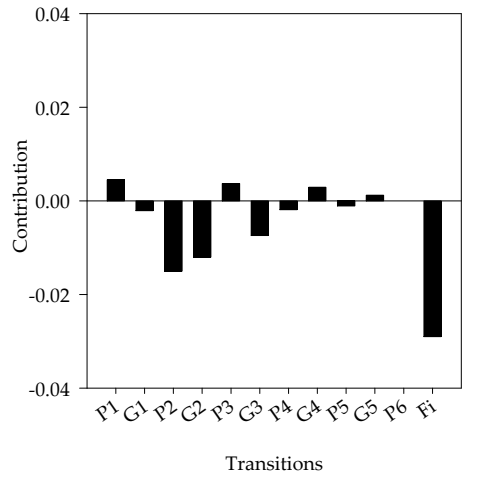

(b)

Figure 3. Life table response experiment (LTRE) analysis on the coffee berry borer Hypothenemus hampei treated with tetracycline $(0.1 \% \mathrm{w} / \mathrm{v})$ compared with control (without antibiotics) and penicillin $(0.1 \% \mathrm{w} / \mathrm{v})$ treatments. The bars show the contribution of each life cycle transition to the reduction in population growth rate $(\lambda)$ when comparing diets. (a) Control vs. Tetracycline and (b) Penicillin vs. Tetracycline. Gi: probability of transition between stages, $P i$ : probability of surviving and remaining in the same stage, Fi: fertility of adult females. (1) Eggs, (2) Larvae, (3) Pre-pupae, (4) Pupae, (5) Juveniles, (6) Adults. 


\subsection{Formatting of Mathematical Components}

For the projection matrix, variations in the size and age structure of a population $\mathbf{N}$ through time $t$ and $t+1$ were computed from the equation:

$$
\mathrm{N}_{t+1}=\mathrm{AN}_{t}
$$

where $\mathbf{A}$ is a population matrix and $\mathbf{N}$ is a vector describing the age of structured population. Thus, the projection matrix was:

$$
\left[\begin{array}{l}
n_{1} \\
n_{2} \\
n_{3} \\
n_{4} \\
n_{5} \\
n_{6}
\end{array}\right]_{t+1} \mathrm{~A}=\left[\begin{array}{cccccc}
\boldsymbol{P}_{1} & 0 & 0 & 0 & 0 & \boldsymbol{F}_{1} \\
\boldsymbol{G}_{1} & \boldsymbol{P}_{2} & 0 & 0 & 0 & 0 \\
0 & \boldsymbol{G}_{2} & \boldsymbol{P}_{3} & 0 & 0 & 0 \\
0 & 0 & \boldsymbol{G}_{3} & \boldsymbol{P}_{4} & 0 & 0 \\
0 & 0 & 0 & \boldsymbol{G}_{4} & \boldsymbol{P}_{5} & 0 \\
0 & 0 & 0 & 0 & \boldsymbol{G}_{5} & \boldsymbol{P}_{6}
\end{array}\right] \times \mathrm{N}=\left[\begin{array}{c}
n_{1} \\
n_{2} \\
n_{3} \\
n_{4} \\
n_{5} \\
n_{6}
\end{array}\right]_{t}
$$

\section{Discussion}

\subsection{Wolbachia in Insects and Status in the $C B B$}

Wolbachia are widespread and common insect endosymbionts and have been detected in more than $66 \%$ of insect species tested [7,39]. In many species, infection rate is variable; infected individuals within a species ranges from $<3 \%$ to $100 \%$ [40,41]. Also, the titer of Wolbachia can be as low as $<0.01$ or as high as $>1200$ cells per insect cell $[42,43]$ (though Wolbachia are not uniformly distributed throughout the insect but concentrated in special organs). Furthermore, there are populations with high infection frequency of Wolbachia, but titer per individual is low. This was demonstrated in the bark beetle Pytogenes chalcographus (Linneaus), which had infection frequencies of $85 \%-100 \%$, but the titer per cell was $<0.5$ [44]. It is not clear if there is a threshold titer for Wolbachia to affect insects.

In the case of the $\mathrm{CBB}$, there are no published studies that reported the infection rate or titer. Vega et al. [20] detected Wolbachia in ten of fifteen samples, which could suggest a high infection frequency, but they did not report how many individuals were tested per sample. The data reported here are averages from pooled samples, so there is no way of detecting variation in titer among individuals.

In this study the success rate for amplifying Wolbachia using conventional PCR was $<10 \%$. $16 \mathrm{~S}$ sequencing showed a low relative proportion of Wolbachia in the CBB microbiota of adult females reared in artificial diets and collected from the field, $0.49 \%$ and $0.16 \%$ respectively [31]. A low titer of Wolbachia in the CBB may explain the difficulty of amplification, as Vega et al. [20] suggested. Yet the data presented here suggest that even a low titer of Wolbachia can have a significant effect on insect reproductive biology. Furthermore, the difference between treatments with $0.49 \%$ relative proportion of Wolbachia in females from control diet and $0.04 \%$ in females from tetracycline suggests the possibility of a dosage-dependent effect.

\subsection{Placement of CBB Symbionts in Wolbachia Supergroups}

For Wolbachia classification the wsp gene was preferred by Zhuo et al. [5]; wsp is evolving more rapidly than $16 \mathrm{~S}$ rDNA and ftsZ genes. According to phylogenetic studies using these three genes, the genus Wolbachia is divided into eight supergroups $(\mathrm{A}-\mathrm{H})$ [45-48]. The supergroups A and B are exclusively found in arthropods and are the most common; $\mathrm{C}$ and $\mathrm{D}$ are found in nematodes. The remaining supergroups $(\mathrm{E}-\mathrm{H})$ have been proposed more recently and may be less common $[46,47,49]$. However, the diversity and the number of supergroups in Wolbachia are increasing as different genes are explored: for example, eleven supergroups were recognized when the additional genes glt $A$ and groEL were included [50]. 
The term supergroup is used to define a clade of phylogenetically related strains [5,49]; the Wolbachia in CBB females from Puerto Rico belonged to supergroup A, while the 'consensus sequence' from India and Brazil belonged to supergroup B [20] (Figure 1). The subdivision of Wolbachia into supergroups was done in response to its high genetic diversity compared with other endosymbionts [49]. However, to our knowledge there are no studies demonstrating functional differences between Wolbachia supergroups A and B. More studies should be conducted to determine the diversity and distribution of Wolbachia strains in the CBB, and to elucidate the significance of this diversity in CBB biology.

\subsection{Antibiotic Treatments and Their Effect on CBB Reproduction and Fitness}

The effect of tetracycline on insect reproduction and fitness of Wolbachia-infected insects can result from curing or reducing Wolbachia infection, but could also reflect direct toxicity on host physiology [14]. It is also possible that tetracycline caused other changes in the microbiota unrelated to Wolbachia. These possible explanations are explored further in Mariño [31]. To reduce the possibility that the observed effects on CBB were a result of direct antibiotic toxicity or other changes in the microbiota, we included a parallel treatment with penicillin G; penicillin $\mathrm{G}$ is not effective against Wolbachia $[3,24,25]$. Tetracycline and penicillin differ in their modes of action and ranges of activity; however, both antibiotics can affect directly the fecundity and survival of insects [51-53]. Moreover, in this study penicillin did not affect reproduction in the $\mathrm{CBB}$, the reverse of what would occur if the observed effects were due to toxicity. It also reduces (but no eliminates) the possibility that the results reflect the effect of antibiotics on nontarget groups of bacteria, because penicillin has a narrower spectrum of activity than tetracycline.

Our results showed that females reared on penicillin and control diets produced a similar number of individuals in all stages of development, and there were no significant effects of penicillin on reproduction and life table parameters (Figure 2 and Tables 1-3). Pseudomonas fulva (lizuka and Komagona) is involved in caffeine degradation in the CBB [54]. When P. fulva was eliminated from adult females fed with a mix of three antibiotics including tetracycline, there was a significant reduction in the number of eggs in females fed with the antibiotics [54]. However, reinoculation with P. fulva did not restore the normal reproduction of females. This suggests that $P$. fulva was not responsible for the reduced egg production, and Wolbachia may have been responsible. This reduced reproduction with tetracycline may be due to the effect of reduction of Wolbachia (though this possibility was not mentioned by Ceja-Navarro et al. [54]; Rickettsia, which includes other endosymbiotic bacteria that affect insect reproduction, was recently reported in the CBB [54], but, we did not detect it in CBB from Puerto Rico [31].

Treatment with tetracycline is a well-known method to eliminate Wolbachia from hosts $[11,14,55]$ and test its effect on the reproduction of its hosts. However, our treatment with tetracycline $0.1 \%$ $(\mathrm{w} / \mathrm{v})$ did not eradicate it, even after eleven generations of continuous exposure. Tetracycline $0.1 \%$ or (even less) was enough to remove Wolbachia from other hosts [22,55-57]. Even though the infection was not completely cured, our results strongly suggest a relationship between Wolbachia and the successful reproduction of CBB females. After three generations, the reproduction of females treated with tetracycline started to decrease significantly; by the tenth generation their progeny was less than half compared to females reared in penicillin and control diets (Figure 2A). Also, females treated with tetracycline produced significantly fewer eggs (Figure 2B).

This fertility reduction agrees with data from other beetles in the family Curculionidae. In the date stone beetle (Coccotrypes dactyliperda Fabricius) mated females fed with 3\% tetracycline produced significantly fewer eggs than control females [11]. Similarly, in the rice water weevil (Lissorhoptrus oryzophilus Kuschel) females treated with $0.25 \%-2.5 \%$ tetracycline produced fewer eggs and none of these eggs were viable [13]. The authors of both studies attributed the reduction in fecundity in these species to the elimination of endosymbiotic bacteria, mainly Wolbachia.

Wolbachia are commonly known as reproductive parasites, due their capacity to manipulate the reproduction of their hosts in different ways to enhance their own transmission [1]. However, some 
Wolbachia can be mutualists [6], involved in nutritional mechanisms reported in Drosophila melanogaster [58] and recently in Cimex lectularius (Linneaus) [59] and Aedes albopictus (Skuse) [60]. Our results suggest that Wolbachia plays an important role in $\mathrm{CBB}$ reproduction.

\subsection{Sex Ratio}

Infection by endosymbiotic bacteria has been shown to be associated with female-biased sex ratios [1,22,61-63]. In some insects, females cured with antibiotics produce more males or only males [64-69].

In the only previous study of Wolbachia in CBB, Vega et al. [20] suggested that Wolbachia plays a role in the female-biased sex ratio observed in the CBB. Our results showed that Wolbachia's effects on the sex ratio are at best indirect: females treated with tetracycline produced significantly fewer daughters than females from controls, but tetracycline did not affect significantly the number of males produced (Table 1). The less skewed sex ratio observed with tetracycline was more a consequence of the reduction in the number of females than the production of more males.

Contrary to Vega et al. [20], we suggest that Wolbachia is not involved in the sex determination of $\mathrm{CBB}$; a significant increase in the number of males in progenies from females treated with tetracycline would be the expected result if Wolbachia were involved in sex determination. Other mechanisms, mainly the sex determination systems haplodiploidy and functional haplodiploidy, are known to induce highly female-biased sex ratios [22,70]. Functional haplodiploidy is the sex determination system described for the CBB [71]; in this system, the sex ratio distortion is a consequence of high male mortality, which occurs due to the loss of paternal chromosomes $[9,12]$.

However, this result needs to be confirmed through the production of Wolbachia-cured lines. The best method to assess the impact of Wolbachia on sex determination in its hosts is to compare an infected line with a Wolbachia-cured line [72]. It is also important to determine the minimum dose of tetracycline needed to completely cure Wolbachia infections; 3\% (w/v) tetracycline eliminated endosymbiotic bacteria, including Wolbachia, from Coccotrypes dactyliperda (Coleoptera: Curculionidae) [11]. However, such high concentrations also exacerbate toxicity issues. Alternatively, another antibiotic like rifampicin could be used; rifampicin is also effective against Wolbachia [14,24].

Relatively few studies have measured the effect of Wolbachia in arthropod population dynamics. Demographic studies allow comparing the growth potential for a population under different conditions; life time response experiments (LTREs) deconstruct differences on population growth into contributions from each life cycle transition [73]. In the case of insect pests like the CBB, this type of analysis could provide insight into which specific life cycle transition could be targeted for management.

Wolbachia-free populations of Liposcelis tricolor (Badonnel), (Psocoptera: Liposcelididae) had lower performance in all life parameters evaluated: intrinsic rate of increase $r m$, net reproductive value $R_{0}$, and mean generation time. Similarly, our data showed that tetracycline reduced the values of all life table parameters evaluated in the CBB. The LTRE analysis identified the fecundity of adult females as the stage contributing most to the reduction of $\lambda$ (Figure 3). Taken together, these data suggest that Wolbachia are important for successful reproduction of the CBB.

\section{Conclusions}

In this study we detected Wolbachia supergroup A in adult CBB females from Puerto Rico. The relative proportion of Wolbachia in the CBB microbiome is very low, less than $1 \%$.

Wolbachia appears to contribute to reproductive success in the CBB: antibiotic treatment significantly reduced the proportion of Wolbachia, and had negative effects on reproduction and population dynamic of CBB. This result opens the door to the possibility of CBB biocontrol mediated by manipulating Wolbachia infection, either by reducing Wolbachia infection or encouraging growth of competing microorganisms in the CBB microbiota. The effects and mechanisms of Wolbachia on $\mathrm{CBB}$ appear to be complex, but our results show they have pronounced effects on the reproductive 
biology of this important pest. Considering the CBB's importance, the possibility of biological control approaches that exploit this new information deserves further investigation.

Acknowledgments: We thank Michelle Cruz for outstanding work in the laboratory, Oscar Ospina for help with 16S analysis, Alberto Sabat and Alex Mercado for advice on life table response analysis, Jennifer Pagán and Fernando Gallardo for advice on rearing CBB. We also thank the NSF CREST-CATEC program and its director Elvira Cuevas for support of undergraduate students. Thanks to University of Puerto Rico Sequencing and Genotyping Facility (UPR- SGF). This research was supported by USDA Cooperative Agreement 58-1245-4-083, and USDA-APHIS-PPQ Z-258, Z-265 and Z-273 (8130-0059, 8272-0685). UPR-SGF is supported by NCRR AABRE grant \#P20 RR16470, Bioprospecting for Plant Protection (Puerto Rico Science and Technology Research Trust.

Author Contributions: Yobana Mariño, Jose C. Verle Rodrigues, and Paul Bayman conceived and designed the experiments; Yobana Mariño performed the experiments and analyzed the data; Yobana Mariño and Paul Bayman drafted the manuscript; Paul Bayman and Jose C. Verle Rodrigues reviewed and edited the manuscript. Paul Bayman and Jose C. Verle Rodrigues obtained funding for the research from the USDA cooperative agreements "Managing the coffee berry borer in Puerto Rico: A multidisciplinary", "IMP of Coffee Berry Borer in Puerto Rico", and "Mitigating invasive species in Puerto Rico" (USDA 58-1245-4-083).

Conflicts of Interest: The authors are owners and officers of Atabei Ecosystems LLC, a startup dedicated to biocontrol and plant health.

\section{Appendix A}

Table A1. Reference sequences of Wolbachia used to determine CBB Wolbachia supergroup classification.

\begin{tabular}{|c|c|c|c|}
\hline Host Insect Species & Order & Wolbachia Supergroup & GenBank Accession No. \\
\hline Aphthona nigriscutis & Coleoptera & A & AF539861 \\
\hline Callosobruchus chinensis & Coleoptera & A & АВ038321 \\
\hline Ceutorhynchus subpubescens & Coleoptera & A & HQ602873 \\
\hline Conotrachelus nenuphar & Coleoptera & A & GU013552 \\
\hline Cynotrachelus coloratus & Coleoptera & A & GU236985 \\
\hline Diabrotica barberi & Coleoptera & A & AY138259 \\
\hline Hypothenemus hampei & Coleoptera & A & KX436087 \\
\hline Hypothenemus hampei & Coleoptera & A & KX436088 \\
\hline Hypothenemus hampei & Coleoptera & A & KX436089 \\
\hline Xylosandrus germanus & Coleoptera & A & AB359043 \\
\hline Aedes albopictus & Diptera & A & KF725080 \\
\hline Drosophila melanogaster & Diptera & A & JF505383 \\
\hline Drosophila sturtevanti & Diptera & A & AY620215 \\
\hline Lutzomia shannoni & Diptera & A & AF237886 \\
\hline Elasmucha signoretii & Heteroptera & A & AB109621 \\
\hline Formica excecta & Hymenoptera & A & AY101196 \\
\hline Nasonia vitripennis & Hymenoptera & A & AF020081 \\
\hline Spalangia cameroni & Hymenoptera & A & DQ380870 \\
\hline Tachinaephagus zealandicus & Hymenoptera & A & DQ380884 \\
\hline Trichogramma kaykai & Hymenoptera & A & AF071912 \\
\hline Ephesia kuehniella & Lepidoptera & A & AB024569 \\
\hline Nymphalis xanthomelas & Lepidoptera & A & AB094392 \\
\hline Callosobruchus chinensis & Coleoptera & $\mathrm{B}$ & AB038339 \\
\hline Conotrachelus nenuphar & Coleoptera & B & GU013550 \\
\hline Conotrachelus nenuphar & Coleoptera & B & GU013551 \\
\hline Hypothenemus hampei & Coleoptera & B & AF389084 \\
\hline Lissorhotrus oryzophilus & Coleoptera & B & HM856616 \\
\hline Tribolium confusum & Coleoptera & B & AF020083 \\
\hline Culex sitiens & Diptera & B & AF317491 \\
\hline Coquilletidia crassipes & Diptera & B & AF317478 \\
\hline Drosophila fundita & Diptera & B & JX134929 \\
\hline Drosophila simulans & Diptera & B & AF020074 \\
\hline Phlebotomus perniciosus & Diptera & B & AF237884 \\
\hline
\end{tabular}


Table A1. Cont.

\begin{tabular}{cccc}
\hline Host Insect Species & Order & Wolbachia Supergroup & GenBank Accession No. \\
\hline Bermisia tabaci & Hemiptera & $\mathrm{B}$ & AF237884 \\
Nesophrosyne silvicola & Hemiptera & $\mathrm{B}$ & $\mathrm{JX134946}$ \\
Orius nagaii & Hemiptera & $\mathrm{B}$ & $\mathrm{AB} 094368$ \\
Tagosedes orizocolus & Hemiptera & $\mathrm{B}$ & $\mathrm{AF020085}$ \\
Mysius plebeius & Heteroptera & $\mathrm{B}$ & $\mathrm{AB} 109566$ \\
Spilostethus hospes & Heteroptera & $\mathrm{B}$ & $\mathrm{AB} 109618$ \\
Acromyrmex echinatior & Hymenoptera & $\mathrm{B}$ & $\mathrm{AF} 472564$ \\
Melittobia digitata & Hymenoptera & $\mathrm{B}$ & $\mathrm{DQ} 487096$ \\
Torymus bedeguaris & Hymenoptera & $\mathrm{B}$ & $\mathrm{AF071915}$ \\
Acraea encedon & Lepidoptera & $\mathrm{B}$ & $\mathrm{AJ} 130716$ \\
Mamestra brassicae & Lepidoptera & $\mathrm{B}$ & $\mathrm{AB} 094375$ \\
\hline
\end{tabular}

Table A2. Results of generalized linear model evaluating the relationship between CBB total population and type of diet (control, penicillin $0.1 \%$, and tetracycline $0.1 \%$ ) and between generations for CBB on diet with tetracycline. ${ }^{* * *} p<0.001 ;{ }^{* *} p<0.01 ;{ }^{*} p<0.05 ; p<0.1$.

\begin{tabular}{ccccc}
\hline Effects & Estimate & Standard Error & Z-Value & $p$ \\
\hline Intercept & 4.108 & 0.0177 & 231.6 & $<0.0001^{* * *}$ \\
Type of diet (control vs. penicillin) & 0.0871 & 0.0109 & 7.93 & 0.0670 \\
Type of diet (control vs. tetracycline) & -0.0804 & 0.0114 & -7.02 & $<0.0001^{* * *}$ \\
Generation $\left(\mathrm{F}_{1}\right.$ vs. $\left.\mathrm{F}_{2}\right)$ & 0.7764 & 0.0199 & 38.91 & $<0.0001^{* * *}$ \\
Generation $\left(\mathrm{F}_{1}\right.$ vs. $\left.\mathrm{F}_{3}\right)$ & 0.8587 & 0.0197 & 43.58 & $<0.0001^{* * *}$ \\
Generation $\left(\mathrm{F}_{1}\right.$ vs. $\left.\mathrm{F}_{4}\right)$ & 0.8285 & 0.0197 & 41.86 & $<0.0001^{* * *}$ \\
Generation $\left(\mathrm{F}_{1}\right.$ vs. $\left.\mathrm{F}_{5}\right)$ & 0.6950 & 0.0202 & 34.38 & $<0.0001^{* * *}$ \\
Generation $\left(\mathrm{F}_{1}\right.$ vs. $\left.\mathrm{F}_{10}\right)$ & 1.172 & 0.0188 & 62.07 & $<0.0001^{* * *}$ \\
\hline
\end{tabular}

\section{References}

1. Werren, J.H. Biology of Wolbachia. Annu. Rev. Entomol. 1997, 42, 587-609. [CrossRef] [PubMed]

2. Brelsfoard, C.L.; Dobson, S.L. Wolbachia-based strategies to control insect pests and disease vectors. Asia Pac. J. Mol. Biol. Biotechnol. 2009, 17, 55-63.

3. Stouthamer, R.; Breeuwer, J.A.; Hurst, G.D. Wolbachia pipientis: Microbial manipulator of arthropod reproduction. Annu. Rev. Microbiol. 1999, 53, 71-102. [CrossRef] [PubMed]

4. Lo, N.; Casiraghi, M.; Salati, E.; Bazzocchi, C.; Bandi, C. How many Wolbachia supergroups exist? Mol. Biol. Evol. 2002, 19, 341-346. [CrossRef] [PubMed]

5. Zhou, W.; Rousset, F.; O'Neill, S. Phylogeny and PCR-based classification of Wolbachia strains using wsp gene sequences. Proc. R. Soc. Lond. B Biol. Sci. 1998, 265, 509-515. [CrossRef] [PubMed]

6. Werren, J.H.; Baldo, L.; Clark, M.E. Wolbachia: Master manipulators of invertebrate biology. Nat. Rev. Microbiol. 2008, 6, 741-751. [CrossRef] [PubMed]

7. Jeyaprakash, A.; Hoy, M. Long PCR improves Wolbachia DNA amplification: Wsp sequences found in $76 \%$ of sixty-three arthropod species. Insect Mol. Biol. 2000, 9, 393-405. [CrossRef] [PubMed]

8. Fry, A.; Palmer, M.; Rand, D. Variable fitness effects of Wolbachia infection in Drosophila melanogaster. Heredity 2004, 93, 379-389. [CrossRef] [PubMed]

9. Dong, P.; Wang, J.-J.; Zhao, Z.-M. Wolbachia infection and its influence on the reproduction of stored-product psocid, Liposcelis tricolor (Psocoptera: Liposcelididae). J. Insect Sci. 2006. [CrossRef] [PubMed]

10. Jia, F.X.; Yang, M.S.; Yang, W.J.; Wang, J.J. Influence of continuous high temperature conditions on Wolbachia infection frequency and the fitness of Liposcelis tricolor (Psocoptera: Liposcelididae). Environ. Entomol. 2009, 38, 1365-1372. [CrossRef] [PubMed]

11. Zchori-Fein, E.; Borad, C.; Harari, A.R. Oogenesis in the date stone beetle, Coccotrypes dactyliperda, depends on symbiotic bacteria. Physiol. Entomol. 2006, 31, 164-169. [CrossRef]

12. Engelstädter, J.; Telschow, A. Cytoplasmic incompatibility and host population structure. Heredity 2009, 103, 196-207. [CrossRef] [PubMed] 
13. Chen, S.-J.; Lu, F.; Cheng, J.-A.; Jiang, M.-X.; Way, M.O. Identification and biological role of the endosymbionts Wolbachia in rice water weevil (Coleoptera: Curculionidae). Environ. Entomol. 2012, 41, 469-477. [CrossRef] [PubMed]

14. Dedeine, F.; Vavre, F.; Fleury, F.; Loppin, B.; Hochberg, M.E.; Boulétreau, M. Removing symbiotic Wolbachia bacteria specifically inhibits oogenesis in a parasitic wasp. Proc. Natl. Acad. Sci. USA 2001, 98, 6247-6252. [CrossRef] [PubMed]

15. Zabalou, S.; Riegler, M.; Theodorakopoulou, M.; Stauffer, C.; Savakis, C.; Bourtzis, K. Wolbachia-induced cytoplasmic incompatibility as a means for insect pest population control. Proc. Natl. Acad. Sci. USA 2004, 101, 15042-15045. [CrossRef] [PubMed]

16. Damon, A. A review of the biology and control of the coffee berry borer, Hypothenemus hampei (Coleoptera: Scolytidae). Bull. Entomol. Res. 2000, 90, 453-465. [CrossRef] [PubMed]

17. Soto-Pinto, L.; Perfecto, I.; Caballero-Nieto, J. Shade over coffee: Its effects on berry borer, leaf rust and spontaneous herbs in Chiapas, Mexico. Agrofor. Syst. 2002, 55, 37-45. [CrossRef]

18. Jaramillo, J.; Borgemeister, C.; Baker, P. Coffee berry borer Hypothenemus hampei (Coleoptera: Curculionidae): Searching for sustainable control strategies. Bull. Entomol. Res. 2006, 96, 223-233. [CrossRef] [PubMed]

19. Vega, F.E.; Infante, F.; Castillo, A.; Jaramillo, J. The coffee berry borer, Hypothenemus hampei (Ferrari) (Coleoptera: Curculionidae): A short review, with recent findings and future research directions. Terr. Arthropod Rev. 2009, 2, 129-147.

20. Vega, F.E.; Benavides, P.; Stuart, J.A.; O'Neill, S.L. Wolbachia infection in the coffee berry borer (Coleoptera: Scolytidae). Ann. Entomol. Soc. Am. 2002, 95, 374-378. [CrossRef]

21. Portilla, M. Mass rearing technique for Cephalonomia stephanoderis (Hymenoptera: Bethylidae) on Hypothenemus hampei (Coleoptera: Scolytidae) developed using cenibroca artificial diet. Rev. Colomb. Entomol. 1999, 25, 57-66.

22. Werren, J.H.; Beukeboom, L.W. Sex determination, sex ratios, and genetic conflict. Annu. Rev. Ecol. Syst. 1998, 29, 233-261. [CrossRef]

23. Ballard, J.; Melvin, R. Tetracycline treatment influences mitochondrial metabolism and mtDNA density two generations after treatment in Drosophila. Insect Mol. Biol. 2007, 16, 799-802. [CrossRef] [PubMed]

24. Fenollar, F.; Maurin, M.; Raoult, D. Wolbachia pipientis growth kinetics and susceptibilities to 13 antibiotics determined by immunofluorescence staining and real-time PCR. Antimicrob. Agents Chemother. 2003, 47, 1665-1671. [CrossRef] [PubMed]

25. Taylor, M.; Bandi, C.; Hoerauf, A.; Lazdins, J. Wolbachia bacteria of filarial nematodes: A target for control? Parasitol. Today 2000, 16, 179-180. [CrossRef]

26. Kondo, N.; Ijichi, N.; Shimada, M.; Fukatsu, T. Prevailing triple infection with Wolbachia in Callosobruchus chinensis (Coleoptera: Bruchidae). Mol. Ecol. 2002, 11, 167-180. [CrossRef] [PubMed]

27. Maddison, W.P.; Maddison, D. Mesquite: A Modular System for Evolutionary Analysis. Available online: http:/ / mesquiteproject.org (accessed on 12 August 2016).

28. Tamura, K.; Stecher, G.; Peterson, D.; Filipski, A.; Kumar, S. Mega6: Molecular evolutionary genetics analysis version 6.0. Mol. Biol. Evol. 2013, 30, 2725-2729. [CrossRef]

29. Caporaso, J.G.; Lauber, C.L.; Walters, W.A.; Berg-Lyons, D.; Huntley, J.; Fierer, N.; Owens, S.M.; Betley, J.; Fraser, L.; Bauer, M. Ultra-high-throughput microbial community analysis on the illumina hiseq and miseq platforms. ISME J. 2012, 6, 1621-1624. [CrossRef] [PubMed]

30. Caporaso, J.G.; Kuczynski, J.; Stombaugh, J.; Bittinger, K.; Bushman, F.D.; Costello, E.K.; Fierer, N.; Pena, A.G.; Goodrich, J.K.; Gordon, J.I. Qiime allows analysis of high-throughput community sequencing data. Nat. Methods 2010, 7, 335-336. [CrossRef] [PubMed]

31. Mariño, Y. Reproduction, sex ratio and bacterial communities of the coffee berry borer Hypothenemus hampei F. (Coleoptera: Curculionidae). Ph.D. Thesis, University of Puerto Rico, Río Piedras, Puerto Rico, 2015.

32. Bergamin, J. Contribuição para o conhecimento da biologia da broca do café Hypothenemus hampei (Ferrari, 1867) (Col. Ipidae). Arq. Inst. Biol. 1943, 14, 31-72. (In Portuguese)

33. Ruiz-Cárdenas, R.; Baker, P. Life table of Hypothenemus hampei (Ferrari) in relation to coffee berry phenology under colombian field conditions. Sci. Agricola 2010, 67, 658-668. [CrossRef]

34. Romero, J.; Cortina, H. Tablas de vida de Hypothenemus hampei (Coleoptera: Curculionidae: Scolytinae) sobre tres introducciones de café. Rev. Colomb. Entomol. 2007, 33, 10-16. (In Spanish) 
35. Caswell, H. Matrix Population Models: Construction, Analysis and Interpretation, 2nd ed.; Sinauer: Sunderland, MA, USA, 2001.

36. Stubben, C.; Milligan, B. Estimating and analyzing demographic models using the popbio package in R. J. Stat. Softw. 2007, 22, 1-23. [CrossRef]

37. R Core Team. A Languaje and Environment for Statistical Computing; R Foundation for Statistical Computing: Vienna, Austria, 2013.

38. Kyei-Poku, G.; Giladi, M.; Coghlin, P.; Mokady, O.; Zchori-Fein, E.; Floate, K. Wolbachia in wasps parasitic on filth flies with emphasis on Spalangia cameroni. Entomol. Exp. Appl. 2006, 121, 123-135. [CrossRef]

39. Hilgenboecker, K.; Hammerstein, P.; Schlattmann, P.; Telschow, A.; Werren, J.H. How many species are infected with Wolbachia?-A statistical analysis of current data. FEMS Microbiol. Lett. 2008, 281, 215-220. [CrossRef] [PubMed]

40. Rasgon, J.L.; Scott, T.W. An initial survey for Wolbachia (Rickettsiales: Rickettsiaceae) infections in selected California mosquitoes (Diptera: Culicidae). J. Med. Entomol. 2004, 41, 255-257. [CrossRef] [PubMed]

41. Tagami, Y.; Miura, K. Distribution and prevalence of Wolbachia in Japanese populations of Lepidoptera. Insect Mol. Biol. 2004, 13, 359-364. [CrossRef] [PubMed]

42. Bordenstein, S.R.; Marshall, M.L.; Fry, A.J.; Kim, U.; Wernegreen, J.J. The tripartite associations between bacteriophage, Wolbachia, and arthropods. PLoS Pathog. 2006, 2, e43.

43. Ahantarig, A.; Trinachartvanit, W.; Kittayapong, P. Relative Wolbachia density of field-collected Aedes albopictus mosquitoes in Thailand. J. Vector Ecol. 2008, 33, 173-177. [CrossRef]

44. Wolfgang, A.; Markus, R.; Dimitrios, N.; Christian, S. Evidence for low-titre infections in insect symbiosis: Wolbachia in the bark beetle Pityogenes chalcographus (Coleoptera, scolytinae). Environ. Microbiol. 2009, 11, 1923-1933. [CrossRef] [PubMed]

45. Werren, J.H.; Windsor, D.M. Wolbachia infection frequencies in insects: Evidence of a global equilibrium? Proc. R. Soc. Lond. B Biol. Sci. 2000, 267, 1277-1285. [CrossRef] [PubMed]

46. Lo, N.; Paraskevopoulos, C.; Bourtzis, K.; O’Neill, S.; Werren, J.; Bordenstein, S.; Bandi, C. Taxonomic status of the intracellular bacterium Wolbachia pipientis. Int. J. Syst. Evol. Microbiol. 2007, 57, 654-657. [CrossRef] [PubMed]

47. Ros, V.I.; Fleming, V.M.; Feil, E.J.; Breeuwer, J.A. How diverse is the genus wolbachia? Multiple-gene sequencing reveals a putatively new Wolbachia supergroup recovered from spider mites (Acari: Tetranychidae). Appl. Environ. Microbiol. 2009, 75, 1036-1043. [CrossRef]

48. Baldo, L.; Hotopp, J.C.D.; Jolley, K.A.; Bordenstein, S.R.; Biber, S.A.; Choudhury, R.R.; Hayashi, C.; Maiden, M.C.; Tettelin, H.; Werren, J.H. Multilocus sequence typing system for the endosymbiont Wolbachia pipientis. Appl. Environ. Microbiol. 2006, 72, 7098-7110. [CrossRef] [PubMed]

49. Baldo, L.; Werren, J.H. Revisiting Wolbachia supergroup typing based on wsp: Spurious lineages and discordance with mlst. Curr. Microbiol. 2007, 55, 81-87. [CrossRef] [PubMed]

50. Augustinos, A.A.; Santos-Garcia, D.; Dionyssopoulou, E.; Moreira, M.; Papapanagiotou, A.; Scarvelakis, M.; Doudoumis, V.; Ramos, S.; Aguiar, A.F.; Borges, P.A. Detection and characterization of Wolbachia infections in natural populations of aphids: Is the hidden diversity fully unraveled? PLoS ONE 2011, 6, e28695. [CrossRef]

51. Srivastava, P.; Auclair, J. Effects of antibiotics on feeding and development of the pea aphid, Acyrthosiphon pisum (Harris) (Homoptera: Aphididae). Can. J. Zool. 1976, 54, 1025-1029. [CrossRef]

52. Büyükgüzel, K.; Yazgan, Ş. Effects of antimicrobial agents on the survival and development of larvae of Pimpla turionellae L. (Hymenoptera: Ichneumonidae) reared on an artificial diet. Turk. J. Zool. 2001, 26, 111-119.

53. Dale, C.; Welburn, S. The endosymbionts of tsetse flies: Manipulating host-parasite interactions. Int. J. Parasitol. 2001, 31, 628-631. [CrossRef]

54. Ceja-Navarro, J.A.; Vega, F.E.; Karaoz, U.; Hao, Z.; Jenkins, S.; Lim, H.C.; Kosina, P.; Infante, F.; Northen, T.R.; Brodie, E.L. Gut microbiota mediate caffeine detoxification in the primary insect pest of coffee. Nat. Commun. 2015. [CrossRef] [PubMed]

55. Kageyama, D.; Traut, W. Opposite sex-specific effects of Wolbachia and interference with the sex determination of its host Ostrinia scapulalis. Proc. R. Soc. Lond. B Biol. Sci. 2004, 271, 251-258. [CrossRef]

56. Charlat, S.; Davies, N.; Roderick, G.K.; Hurst, G.D. Disrupting the timing of Wolbachia-induced male-killing. Biol. Lett. 2007, 3, 154-156. [CrossRef] 
57. Breeuwer, J. Wolbachia and cytoplasmic incompatibility in the spider mites Tetranychus urticae and T. turkestani. Heredity 1997, 79, 41-47. [CrossRef]

58. Brownlie, J.C.; Cass, B.N.; Riegler, M.; Witsenburg, J.J.; Iturbe-Ormaetxe, I.; McGraw, E.A.; O’Neill, S.L. Evidence for metabolic provisioning by a common invertebrate endosymbiont, Wolbachia pipientis, during periods of nutritional stress. PLoS Pathog. 2009, 5, e1000368. [CrossRef] [PubMed]

59. Nikoh, N.; Hosokawa, T.; Moriyama, M.; Oshima, K.; Hattori, M.; Fukatsu, T. Evolutionary origin of insect-Wolbachia nutritional mutualism. Proc. Natl. Acad. Sci. USA 2014, 111, 10257-10262. [CrossRef] [PubMed]

60. Molloy, J.C.; Sommer, U.; Viant, M.R.; Sinkins, S.P. Wolbachia modulates lipid metabolism in Aedes albopictus mosquito cells. Appl. Environ. Microbiol. 2016, 82, 3109-3120. [CrossRef] [PubMed]

61. Weeks, A.R.; Velten, R.; Stouthamer, R. Incidence of a new sex-ratio-distorting endosymbiotic bacterium among arthropods. Proc. R. Soc. Lond. Biol. 2003, 270, 1857-1865. [CrossRef] [PubMed]

62. Jiggins, F.M.; Hurst, G.D.; Majerus, M.E. Sex-ratio distorting Wolbachia causes sex-role reversal in its butterfly host. Proc. R. Soc. Lond. B Biol. Sci. 2000, 267, 69-73. [CrossRef] [PubMed]

63. Dyson, E.A.; Hurst, G.D. Persistence of an extreme sex-ratio bias in a natural population. Proc. Nat. Acad. Sci. USA 2004, 101, 6520-6523. [CrossRef] [PubMed]

64. Giorgini, M. Induction of males in thelytokous populations of Encarsia meritoria and Encarsia protransvena: A systematic tool. BioControl 2001, 46, 427-438. [CrossRef]

65. Pijls, J.; Steenbergen, H.J.V.; Alphen, J.J.V. Asexuality cured: The relations and differences between sexual and asexual Apoanagyrus diversicornis. Heredity 1996, 76, 506-513. [CrossRef]

66. Hurst, G.D.; Johnson, A.P.; vd Schulenburg, J.H.G.; Fuyama, Y. Male-killing Wolbachia in Drosophila: A temperature-sensitive trait with a threshold bacterial density. Genetics 2000, 156, 699-709. [PubMed]

67. Stouthamer, R.; Luck, R.F.; Hamilton, W. Antibiotics cause parthenogenetic Trichogramma (Hymenoptera: Trichogrammatidae) to revert to sex. Proc. Nat. Acad. Sci. USA 1990, 87, 2424-2427. [CrossRef]

68. Majerus, M.; Knowles, B.; Bertrand, D.; Hurst, G.D. Extreme variation in the prevalence of inherited male-killing microorganisms between three populations of Harmonia axyridis (Coleoptera: Coccinellidae). Heredity 1998, 81, 683-691. [CrossRef]

69. Pannebakker, B.A.; Beukeboom, L.W.; van Alphen, J.J.; Brakefield, P.M.; Zwaan, B.J. The genetic basis of male fertility in relation to haplodiploid reproduction in Leptopilina clavipes (Hymenoptera: Figitidae). Genetics 2004, 168, 341-349. [CrossRef] [PubMed]

70. Ross, L.; Pen, I.; Shuker, D.M. Genomic conflict in scale insects: The causes and consequences of bizarre genetic systems. Biol. Rev. 2010, 85, 807-828. [CrossRef] [PubMed]

71. Brun, L.O.; Stuart, J.; Gaudichon, V.; Aronstein, K.; French-Constant, R. Functional haplodiploidy: A mechanism for the spread of insecticide resistance in an important international insect pest. Proc. Natl. Acad. Sci. USA 1995, 92, 9861-9865. [CrossRef] [PubMed]

72. Stouthamer, R.; Mark, F. Influence of antibiotics on the offspring production of the Wolbachia-infested parthenogenetic parasitoid Encarsia formosa. J. Invertebr. Pathol. 2002, 80, 41-45. [CrossRef]

73. Caswell, H. Life table response experiment analysis of the stochastic growth rate. J. Ecol. 2010, 98, 324-333. [CrossRef]

(C) 2017 by the authors; licensee MDPI, Basel, Switzerland. This article is an open access article distributed under the terms and conditions of the Creative Commons Attribution (CC-BY) license (http://creativecommons.org/licenses/by/4.0/). 